\title{
IDENTIDAD SOCIOMUSICAL DE LOS JÓVENES AYMARAS: LA MÚSICA SOUND
}

\author{
BERNARDO GUERRERO JIMÉNEZ*
}

\begin{abstract}
RESUMEN
El presente artículo discute algunas ideas en torno a la música sound como dispositivo de producción de identidad entre los jóvenes aymaras del norte grande de Chile, radicado en las ciudades, en especial en Iquique. Se reflexiona en torno al concepto de identidad cultural y enfatiza la idea de como la música, en este caso, la sound se transforma en un vehículo para expresar por un lado modernidad, y por la otra, seguir afirmando parte de su tradición.

Palabras Clave: IdentidAd, Juventud AyMARA, Música

* Sociólogo. Universidad Arturo Prat, Iquique, Chile.

Artículo escrito en base a la ponencia «Identidad cultural y música sound», presentada en las jornadas de «Música popular e identidad cultural», realizada en Iquique en octubre de 2006.

Correo electrónico: bernardo.guerrero@unap.cl.
\end{abstract}




\section{RESUMO \\ IDENTIDADE SOCIOMUSICAL DOS JOVENS AYMARAS: A MÚSICA SOUND}

$\mathrm{O}$ presente artigo discute algumas idéias sobre a música sound como dispositivo de produção de identidade entre os jovens aymaras do norte grande do Chile, radicados nas cidades, em especial em Iquique. Reflete-se sobre o conceito de identidade cultural e enfatiza-se a idéia de como a música, neste caso a música sound, transforma-se em um veículo para expressar, por um lado a modernidade, e por outro, a afirmação de parte de sua tradição.

PalaVRas Chave: IdENTIDADE, JuVENTUde AYMARA, Música

\section{Abstract \\ SOCIOMUSICAL IDENTITY OF AYMARAN YOUTH: THE MUSIC SOUND}

This article discusses some ideas around music sound as a device of production of identity among the young Aymaran people of the greater north of Chile, the importance of the cities, especially in Iquique. It reflects around the concept of cultural identity and emphasizes the idea of how music, in this case, sound is transformed into a vehicle, in one way to express modernity, and the other, to continue affirming part of their tradition.

KEY WORDS: IDENTITY, AYMARAN YOUTH, MUSIC 
CON OCASIÓN DE LA fiesta patronal del pueblo de Chijo, estancia de Cariquima, en la comuna de Colchane, al interior de la provincia de Iquique, pudimos observar varios discursos sociomusicales presentes en dicha celebración. En la sede social, el alférez (la máxima autoridad ritual) junto a su señora, recibieron a los invitados. Una banda de sicuris, compuesto por hombres adultos de la comunidad hacían sonar sus instrumentos de viento y de percusión, mientras bailaban dando vueltas en círculos. Ocupaban el centro del espacio. Este grupo es el más tradicional de la cultura andina. A los minutos después ingresó un grupo de lakitas que venían de un pueblo de la quebrada de Camiña. Tocaban instrumentos de vientos y se hacen acompañar de un bombo y de una caja. Un rato más tarde, una banda de Arica, compuesto por cerca de treinta músicos, irrumpieron con sus instrumentos de bronces. Estos tres grupos, representan de una u otra manera, la dinámica identidad sociomusical del pueblo andino. Todo esto ocurría en un espacio cerrado de no más de 60 metros cuadrados. Pero, en el fondo y tras un escenario, se podían ver inmensos parlantes de color negro, instrumentos musicales electrónicos y equipos de amplificación.

En la noche, ese grupo se encargaría de animar la fiesta. Era un grupo de música sound. Hoy es imposible pensar una fiesta patronal de los aymaras sin la presencia de este tipo de conjuntos musicales. A diferencia de las otras expresiones musicales los que interpretan y bailan esta música son jóvenes. Y provienen en su inmensa mayoría de ciudades tales como Iquique y Alto Hospicio. Son jóvenes migrados aymaras que en la ciudad construyeron su propio lenguaje. Su propia identidad. Y la música fue uno de esos instrumentos.

El presente artículo pretende entregar algunos elementos de análisis para entender la emergencia de este tipo de expresión musical y la manera cómo a través de estos fenómenos musicales, los jóvenes aymaras despliegan y reconfiguran fenómenos de identidad.

\section{ANTECEDENTES GENERALES}

En los años 80 del siglo pasado, en el altiplano y quebradas chilenas la cumbia electrónica había logrado desplazar en las fiestas religiosas a los ritmos tradicionales. O a lo más, éstas sólo se reducían a actividades rituales como el floreo de los llamos o el carnaval. En los momentos de diversión la cumbia interpretada por grupos como Los Shappis, Alegría de Augusto Bernardillo, Los Ovnis, Los Doberman (todos 
peruanos), eran los encargados hacer bailar a los jóvenes. La cumbia de origen colombiana, chilenizada por la Sonora Palacios, constituía también un buen motivo para el baile.

Sin embargo, y en forma paulatina, una nueva música se fue introduciendo. Se trata de la música sound. Esta desbordó las fronteras de la sociedad aymara y penetró el tejido popular de la sociedad chilena. Hoy el sound, si bien es cierto, parece estar en retirada, en la década pasada hizo mover, en grandes conciertos a estos jóvenes. Logró además éxitos de ventas, aunque nunca fue un fenómeno que contó con la santificación de la televisión oficial.

Hablamos de una sociedad aymara fuertemente desestructurada por las políticas de chilenización impuesta por el Estado chileno, sobre todo a partir de su instrumento favorito, la escuela. Hablamos de una sociedad aymara que ubicada geográficamente en las fronteras con Perú y Bolivia, era objeto de directrices geopolíticas emanadas de un estado central y obsesionado además por la lógica de una guerra interna y por el potencial ataque de sus viejos enemigos como Perú y Bolivia. Todo este proceso ha sido muy bien inventariado por Van Kessel (1980).

En los 80, la instalación de la Zona Franca de Iquique, que también obedece a la lógica geopolítica (Podestá, 2005:233) impulsada por el régimen de Pinochet va a significar una masificación del consumo. Los bajos costos, en este caso, de equipos electrónicos, de sonidos y de insumos básicos, como casetes, entre otros, va a permitir, que gran parte de la población local acceda a estos bienes. Un ejemplo ayuda a graficar lo anterior. La existencia en Iquique de una industria musical como «Carrero Discos», ${ }^{1}$ sólo se puede entender en relación a los bajos costos de estos insumos.

La lógica de la escuela fiscal instalada en una zona que, según el centro político ubicado en Santiago precisa ser chilenizada, provoca que muchos de los estudiantes que llegan hasta el octavo básico, deban necesariamente desplazarse a las ciudades para continuar sus estudios de la enseñanza media. Más que una opción que ellos deben tomar, es la consecuencia lógica y obligada de un sistema educacional que bajo la idea del progreso, construye como meta la idea de «ser alguien». Y este ideal sólo se consigue abandonando el estilo de vida

1 Ésta es una industria musical exclusivamente regional que graba y distribuye a los cantantes locales y de la región. La música sound es parte importante de su catálogo. Existe desde la década de los 60. 
campesino e insertándose en la ciudad. La experiencia demuestra lo contrario, ya que estos jóvenes sólo alcanzan a ingresar a colegios municipalizados de carácter técnico. Los que llegan a la universidad son pocos. El estudio realizado en los años 80 por el sociólogo Julián González (1987) así parece demostrarlo.

Los jóvenes aymaras por su parte, con una larga tradición musical que se asocia a su religión usan con relativa facilidad instrumentos de vientos y bronces. Estos rituales musicales están asociados a los ciclos productivos relacionados con la agricultura y la ganadería. Los sicuris, lo más tradicional de estas fiestas, que se expresan en el floreo a los llamos en el corral de los mismos, interpretados por los más ancianos de la comunidad, indica la persistencia de una vieja costumbre andina. Con la llegada de los bronces relacionada con la Guerra del Pacífico y con la obligatoriedad del servicio militar, hace que estos instrumentos se masifiquen. Las bandas de bronces constituyen parte importante del paisaje musical andino y del norte grande de Chile. Las grandes fiestas religiosas del norte grande como La Tirana, Ayquina, Las Peñas y San Lorenzo no se pueden entender sin esas bandas.

La cercanía del pueblo aymara con sus hermanos de Perú y Bolivia, y el consumo de música que los andinos hacen de la que transmiten las radioemisoras de esos países, los familiariza con las nuevas tendencias como es, por ejemplo, la música chicha.

\section{IDENTIDAD ÉTNICA Y JÓVENES AYMARAS}

Stuart Hall en su artículo «Quién necesita identidad» (2003) plantea dos situaciones. En la primera hace ver la extraordinaria atención que ha merecido el concepto de identidad, y en segundo lugar, hace mención al proceso de deconstrucción que ha sufrido este concepto. Sugiere ver a la identidad cultural, entre otras tantas consideraciones, del estilo, como una relación, una práctica discursiva, y no como algo integral, originario y unificado (2003:13). Sirva esta idea para conceptualizar el concepto de identidad étnica.

«Lo que los estudios de este tipo demostraban una y otra vez es que la etnicidad no es lo que pensábamos que era». Esta cita la tomo del libro de Gerd Baumann (2001) e ilustra algunas ideas relativas al concepto de etnicidad.

A partir de los años 60, y gracias al aporte de Barth (1969) en su clásico estudio sobre los grupos étnicos y sus fronteras, el concepto de etnicidad alcanzó una dimensión dinámica, no fija ni sustancial. En 
breve la etnicidad, dice este autor, es un concepto dinámico que se inscribe en una lógica mayor, sobre todo la del Estado nacional. La etnicidad es una forma que tienen los pueblos de identificarse, de definirse a sí mismos, o bien de ser definido por los otros. La etnicidad adscribe e identifica. Sobre ciertos rasgos construidos culturalmente sus miembros se reconocen. Uno de los principios de análisis de discurso dice: «el mundo está allí, pero las descripciones del mundo no» (Rorty, en Sayyid y Zac, 1998:254). La etnicidad sería entonces una forma, repetimos, donde los unos y los otros, definen.

El estudio de Barth subrayaba la idea de fronteras. Esto quiere decir que son los propios grupos quienes trazan los límites entre uno y otros. La frontera entre un aymara y un quechua o un chileno o un peruano, está trazada no por la naturaleza sino por la cultura. Somos nosotros mismos, dice Bauman, lo que nos reconocemos como pertenecientes a un grupo, o a otro (2001:79). Esta autora cita a Eriksen: «la etnicidad es principalmente un elemento más de una relación, no una propiedad de un grupo concreto... y está constituida a través del contacto social» (Bauman, 2001:80).

Stuart Hall dice «las identidades nunca se unifican y, en los tiempos de la modernidad tardía, están cada vez más fragmentadas y fracturadas; nunca son singulares, sino construidas de múltiples maneras a través de discursos, prácticas y posiciones diferentes, a menudo cruzadas y antagónicas» (2003:17). Por su parte Arfuch, siguiendo la misma lógica plantea: «La identidad sería entonces no un conjunto de cualidades predeterminadas - raza, color, sexo, clase, cultura, nacionalidad, etc.- - sino una construcción nunca acabada, abierta a la temporalidad, la contingencia, una posicionalidad relacional sólo temporalmente fijada en el juego de las diferencias» (2005:24). Enfatiza más que lo autores anteriores la idea de la discursividad como formadora de identidad. En este sentido, hace la separación, siguiendo a Ricoeur, entre identidad sustancial e identidad narrativa (2004:27). De este modo, la identidad es un permanente volver al pasado, no para quedarse allí, sino para proyectarse hacia el futuro. Quizás más que hablar de pasado, convendría hablar de memoria (Candau, 2001). Es más, hablar de identidad y no de memoria resulta incongruente.

Sobre el concepto de identidad cultural existe una amplia bibliografía que no vamos a revisar aquí Hall (2003), Baumann (2001), Barth (1969), Larraín, Briones (1998). Enfatizamos el carácter dinámico, contradictorio y hasta paradojal del mismo, como una forma de evitar una mirada unidireccional del mismo. Creemos en la identidad 
como un proceso inacabado que tiene por función construir una imagen del colectivo en contraste - no en contraposición- con el otro. Esa imagen que se construye en el proceso de interacción social, recoge y elabora elementos del pasado, lo reubica y le da un sentido coherente con el presente y el futuro. La memoria juega un rol de importancia (Candau, 2001) La identidad es el despliegue de sentido de pertenencia.

La identidad es un proyecto que se despliega bajo condiciones culturales, económicas y políticas concretas. La identidad siempre es histórica. Esto quiere decir que arrastra sobre sí un caudal de contenidos y de formas que en el presente se van reconfigurando de acuerdo a las relaciones que establece con el mundo en que está inserta.

Enfatizando los componentes culturales de la etnicidad, autores tales como Sollors platean que las nociones de nacionalismo, etnicidad y razas son ficciones, continuamente reinventadas. Aquí hay que traer a la memoria el concepto de invención de la tradición, desarrollado por Hobsbawm (2002:7). Fisher dice que la etnicidad es reiventada y reinterpretada en cada generación, por cada individuo (Briones, 1998:61). La metáfora de la invención, dice esta autora, apunta a decir que la etnicidad sólo adquiere entidad cada vez que se marca social y académicamente como problemática (Briones, 1998:61). Una buena discusión sobre el itinerario de esta discusión la encontramos en también en Bazurco (2006). En todo caso, otros autores enfatizan más la idea de la construcción cultural que la ficción cultural. En este ámbito hay que situar estas reflexiones.

Lo mismo sucede con el concepto de juventud. La idea de joven tan frecuentemente utilizada en nuestra vida, tiene su data, si lo miramos desde una perspectiva histórica, a fines del siglo pasado y comienzo del presente. Es en esta etapa donde se crea el concepto de adolescencia, que toma la idea de la «juventud en términos psicológicos y sociológicos como una etapa de turbulencia y de renacimiento, germen de una nueva riqueza para el futuro, una fuerza capaz de aniquilar la miseria del pasado y que promete una regeneración tanto individual como colectiva» (Passerini 1996:383). Este concepto, alcanza en los años 60, su mejor apogeo con los movimientos estudiantiles. Es, en este período, donde surge la imagen del joven andrógino que estaba en contra del orden social establecido. En él radicaba la idea de un futuro próspero, justo y para todos. La idea del adolescente y del joven estaba asociado al género masculino y a la clase media. Esta fue la imagen que predominó como modelo. 
La idea es que la sociedad occidental elaboró un modelo de juventud y adolescencia. Así por ejemplo, el fascismo italiano diseñó el tópico juvenil en base a tres atributos: «joven, varón y guerrero» (Passerini 1996:388). Mientras que a las jóvenes mujeres se les hablaba de que no se hicieran grandes ilusiones de estudiar, ya que sólo pueden «convertirse en buenas amas de casas y buenas madres» (Passerini 1996:391).

Por otro lado, en la sociedad norteamericana el tema de los jóvenes, a partir de los años cincuenta, alcanza a nivel del lenguaje cinematográfico por ejemplo, un discurso transgresor, donde figuras como Jean Dean o Elvis Presley encauzan una serie de valores que le daría a los jóvenes una condición cultural rubricada por la afirmación del «rebelde sin causa».

La literatura proveniente de los campos de la psicología y de la sociología, por ejemplo, es bastante tópica al hablar de los jóvenes. Se enfatizan sus componentes problemáticos que derivan de la búsqueda de identidad y de autoestima, por ejemplo. Otros la definen como «edad privilegiada de la vida, en la que se descubre el mundo y se forja el futuro». Agregan, además, que «la rebelión es una de las características más relevantes de este período». Los clásicos diccionarios de sociología y psicología la definen como: «Período de la adolescencia en el ser humano, es decir, entre la pubertad y la madurez» (Warren, 1970:194). Por otra parte, el Diccionario de Sociología dice: «Período de la vida humana que comprende desde la adolescencia hasta la madurez» (Pratt, 1963:165). Otros, desde la economía, la definen en función del mercado. Es decir, aquellos que tienen desde los catorce hasta los veinticuatro años (Laurie 1969:11). Otros lo especifican aun más y esta última edad la vinculan al hecho objetivo de la obtención de la independencia económica.

Cada cultura, y en especial Occidente, construyó su discurso de la juventud de acuerdo a sus pretensiones y anhelos. Walter Benjamín en el año 1914 declaraba: «La juventud está en el centro del lugar donde nace lo nuevo», agregando enseguida: «Existe de nuevo una generación que quiere tener dudas, pero la duda está en ninguna parte» (Passerini 1996:445). Otros autores más radicales plantean que el teenager ha muerto, ya que en la actualidad otras edades parecen ser más atractivas, como por ejemplo, la que va entre los seis y los nueve años. Passerini plantea que más que hablar de una condición juvenil, hay que hablar de condiciones juveniles. El plural alude a la idea de que 
bajo una misma cultura, por procesos de migración, entre otros, es más conveniente hablar de juventudes en vez de juventud. Para el caso del norte grande eso es más elocuente, toda vez que vemos jóvenes aymaras, jóvenes urbanos, etc, y en ambas categorías es posible hallar diferencias.

Habría que pensar el paso de una juventud que dudaba a una juventud no sólo que no duda, sino que no le interesa dudar. Aquí nos centramos más que nada en la idea de una juventud que no se siente identificada con los megarrelatos emancipatorios de los sesenta, ni de aquella que buscaba en la filosofía hippie la comunidad donde iba a prosperar la paz y menos aún la idea que identifica a los jóvenes con el barrio, el club deportivo, la iglesia o el baile religioso. En este sentido, la juventud de los setenta, al menos en la retórica de la canción popular, se representaba a sí misma como portadora de un discurso salvífico. El sociólogo español Juan Cueto en su Mitología de la Modernidad, plantea que el descubrimiento de los jóvenes obedece más que a nada a una motivación económica. Se les descubre como sujetos de consumo para la emergente sociedad de consumo. Pero, es el pensamiento social, continúa, el que los decreta como «héroes del mercado de consumo de masas» (1982:12). Los jóvenes son objeto de una cruel paradoja. Son halagados por la sociedad de consumo, pero negados como ciudadanos de pleno derecho.

En la década de los sesenta los jóvenes alcanzan la estatura del mito. Todos los ismos imaginables se le achacan: hedonismo, utopismo, narcisismo, además de la consabida rebelión contra el padre, nueva clase revolucionaria (Mayo de París del 68). Los jóvenes fueron vistos como héroes de lo político y lo social. Pero, en los ochenta, los jóvenes siguen siendo héroes, pero sólo del consumo. Desaparecieron de la arena de lo político y de lo social. Dice Cueto que ya son la metáfora de lo rebelde contra la dominación ideológica. Citamos a este analista: «Las jergas provocadoras, las indumentarias extravagantes, los radicalismos eróticos, los extremismos ideológicos, los sonidos revolucionarios, los nuevos gestos asfálticos, no inquietan como antes a la sociedad adulta. Y lo que es más significativo — continúa - han dejado de suscitar teorías, tesis, sociologías, filosofías, literaturas» (Cueto, 1982:13).

Pero, los problemas de los jóvenes siguen existiendo: cesantía, drogadicción, falta de expectativas. Dice sugerentemente el autor citado: «el joven se ha convertido en un hecho audiovisual. Se le ha quitado el derecho a la palabra y al escándalo, a cambio de concederle el 
privilegio de las imágenes y los sonidos en candelero» (Cueto, 1982:13). Concluye que lo juvenil sigue siendo el gran objeto de la moda, pero el joven ya no es el sujeto de moda.

La idea de juventud al igual que el concepto de identidad cultural tiene de común su carácter de construcción y de ser moldeado por la cultura en donde se desarrolla. Los jóvenes aymaras que viven en la ciudad no están ajenos a estos procesos. Mantienen con sus pueblos de origen una relación fuerte, Acuden a ello en épocas de vacaciones y para las fiestas religiosas. Pero, es la ciudad su centro de operaciones. Y ciertos lugares de ésta. González en su estudio ya citado sobre los jóvenes aymaras ensaya la siguiente definición: «aquella población que procede efectivamente del interior de Iquique, que desciende de familias aymaras vinculadas a las actividades agrícola-ganadera basada en una tecnología simbólica, proveniente de sus antepasados; nos concentramos además en las edades entre 18 y 29 años» (1987:7). Esta definición nos permite identificar el soporte sobre el que se levanta la música llamada sound.

\section{DE LA MÚSICA CHICHA A LA MÚSICA SOUND}

Para entender el desarrollo de la música sound hay que entender la música chicha. Huaynos con guitarras eléctricas, interpretados por jóvenes andinos, constituyen la marca de fábrica de este nuevo estilo. La mejor comprensión de esta forma musical, hay que ubicarla además, en el contexto de la migración y de la pobreza que vive la población andina en Lima.

La llamada música chicha ofrece entonces una variante que la música andina tradicional no podía seguir ofreciendo. En un ambiente de fronteras abiertas, por no decir de globalización, las influencias musicales se expanden por todo el ancho de la marginalidad que se produce en ciudades como Lima producto de las migraciones que provienen de las sierra. El hábitat de esta nueva música son los llamados pueblos jóvenes.

Estos músicos reemplazan el charango y la quena por las guitarras eléctricas, pero siguen manteniendo las armonías andinas. La música chicha tiene más resonancias andinas que la música sound, pero ambas beben de una misma tradición.

La Chicha, la corriente tropical andina de la cumbia peruana, fue por un corto tiempo estigmatizada. Pero la masificación de los habitantes serranos en Lima produjo «una interacción entre la cultura an- 
dina y el impacto de los medios masivos de comunicación, como uno de los elementos de mayor relevancia en la socialización, interacción que influyó en las preferencias socioculturales de los jóvenes hijos de inmigrantes y en la búsqueda de una nueva identidad cultural...» (Hurtado, 1995:9).

\section{MÚSICA SOUND: ¿NUEVA MÚSICA ANDINA?}

La música sound tiene dos componentes fuertemente marcados, es urbana y popular. Pero el adjetivo de popular debe ser entendido en función de lo popular étnico. En otras palabras, se trata de una música que congrega en primer lugar a los miles de jóvenes de origen aymara, que habitan la periferia de las ciudades como Arica, Iquique, Calama entre otras. Jóvenes migrantes que viven en la ciudad, ya sea trabajando o estudiando. Son estos jóvenes los que fundan un estilo musical que mezcla elementos aymaras con sonidos citadinos. ¿Pero que es la música sound? Uno de los integrantes del grupo fundador de la movida sound, Amerikan Sound, la define así: «...un nuevo ritmo, más evolucionado, a partir de la cumbia».

Uno de los fundadores de la movida sound es el grupo Amerikan Sound, provenientes, en su mayoría de la localidad de Cariquima, de la comuna de Colchane. Todos ellos jóvenes atraídos por la ciudad y expulsados de su tierra de origen. La ciudad es el único destino que la escuela promueve. En la página web de este grupo se lee:

El 25 de octubre de 1995 en la cuidad de Iquique, Chile, nace Amerika'n Sound. Con la clara idea de hacer un nuevo estilo de música tropical que pegara no sólo en el norte sino que en todo el país, Andrés Farías, tecladista y director del grupo reúne a notables músicos tropicales de la zona: Roberto 'Pipo' Olmos, Raúl Torrejón, Silvio Moscoso, Roberto Moscoso, Jaime Mamani y Pablo Jaiña rápidamente conforman esta agrupación ya que todo estaba perfectamente pensado (www.amerikansound.ya.st).

Son jóvenes que desarrollan estrategias de diversión y de sociabilidad en lugares en la que se reconocen como tal. Todos esos lugares tienen que ver con forma de apropiación del espacio urbano impregnados de connotaciones étnicas. Lugares en que el sello andino es evidente. Sitios en que la pobreza es un factor común. Los andinos que se asientan en la ciudad lo hacen en los cordones marginales de la ciudad. Sus lugares de fiestas también lo serán. Sin embargo, en los años 80, por 
lo menos en la ciudad de Iquique, la movida andina se realizaba en el centro de la ciudad en lugares como las sociedades mutualistas que datan de fines de siglo XIX. Los jóvenes urbanos, no aymaras, desarrollaban su sociabilidad fiestera en el sector sur de la ciudad. En la actualidad es la comuna de Alto Hospicio la que concentran la mayor parte de la emigración andina.

La música sound es la vía en la que los jóvenes aymaras, viven o creen vivir la modernidad de la ciudad. La música sound es el pasaporte que les abre las puertas de una modernidad esquiva. Se vive en una modernidad periférica en la que al ritmo de esta música, los aymaras migrantes expresan su identidad. Pero ya no es una identidad estructurada de acuerdo a los cánones de los ciclos productivos y religiosos. Se trata al contrario de una identidad descentrada de esos ejes.

La identidad que la música sound proyecta y despliega es una identidad mestiza construida por sobre la intersección entre lo tradicional y lo moderno. Entre el ritmo del huayno y los sintetizadores. Es una identidad marcada por las luces de la ciudad, pero de los márgenes. De una ciudad iluminada a medias, ya sea por la marginalidad o por el estigma. El sound es música de «flaiters» diría el estigma que se teje sobre los jóvenes populares y aymaras.

Pero, la música sound no es sólo canto, es también baile. Contiene coreografías que la vinculan, aunque no de un modo directo, a las de ciertos bailes de La Tirana. Los trajes tienen colores que lo remiten a la tradición de las diabladas y de los sambos caporales. Más de este último que de los primeros. El sound es una puesta en escena de cuerpos jóvenes de origen étnico en una ciudad que grita a viva voz su modernidad.

Sin embargo la música sound es música urbana. No tiene en sus componentes, elementos que hablen de la ruralidad o de la etnicidad perdida o abandonada. No es música que deje testimonio de la realidad de los aymaras en la ciudad. No es canción de evidencias. Quizás la única canción que refleja las condiciones de vida, pero de las mujeres, en el sur, es la del grupo «Hechizo» con su tema «La temporera».

El discurso musical sound es también un discurso desideologizado. Sus letras carecen de la denuncia del hip-hop, por ejemplo. Con la excepción de «La temporera» del grupo «Hechizo», que relata la vida de estas mujeres, todos sus temas tienen que ver con los clásicos tópicos de la canción popular. Reiteraciones sobre un mismo paisaje, en este caso e insisto, amoroso, y con una estructura musical relativamente homogénea. 
Sin embargo, al poco andar la música sound se desliga de sus orígenes étnicos y se expande al resto de la población joven marginada y estigmatizada, sobre todo aquellos que consumen pasta base. Aquí la industria musical ve en esta oferta musical una gran posibilidad de negocios. Y advierte además una gran demanda por una música tropical, pero con sabores locales. El sound ya lo dijimos no es más que la cumbia reelaborada en los años 80 . Pretende ser y lo ha logrado, sobre todo en los jóvenes, reemplazar a la cumbia tradicional representada, entre otros, por «La Sonora Palacios».

La movida iquiqueña y nacional en general, se apropia de esta música, que como ya dijimos, redefine la música tropical. Si en estas tierras la cumbia colombiana se chilenizó por obra y gracia de la Sonora Palacios, en el norte grande se andinizó por influencia primero de la música chicha, y luego por la música sound.

La música sound fue un intento por construir fronteras. A través de esa expresión musical, los jóvenes aymaras, encontraron el espacio y el sonido que los identificara como tales. Pero fue tanta su popularidad que rápidamente desplazó sus propias fronteras y enganchó con el mundo popular urbano. En gran parte de la locomoción colectiva de la ciudad, esta música sigue gozando de una amplia popularidad.

\section{A MODO DE CONCLUSIONES}

¿Representa la música sound a la que podemos llamar la nueva música andina? Sí y no. Lo primero porque hay fusión de ritmos. Lo segundo, porque la mezcla es tan audaz que cuesta encontrar el substrato aymara. Pero, sea lo que sea, el estilo sound es una nueva forma de hacer música popular que no sólo se reduce a las canciones, que se interpretan, sino que tiene que ver con una nueva estética: desde la forma de bailar hasta la forma de vestirse. Y más que nada es un fenómeno social que ha calado fuertemente en los sectores populares que son los grandes consumidores de este género musical.

Es en la música sound en la que los jóvenes aymaras se reconocen y proyectan como tal; es un discurso musical, estético y coreográfico claramente reconocido. Y como tal reconoce de forma precisa a quienes portan ese discurso musical: los jóvenes aymaras. Es como mostrar la doble faz de un carné de identidad. Moderno por un lado, y tradicional por el otro. Se afirma un discurso moderno pero se mantienen las claves de una identidad recreada ahora en la ciudad. 
El paisaje musical popular nortino y luego nacional, se vio interpelado por esta forma musical que invadió al país. La gracia de la música sound es que supo abrir sus fronteras más allá de las fronteras étnicas que su cultura de origen le fijaba.

Más allá del éxito de grupos nacidos en esta zona como Amerikan Sound y Tropikal Sound, los jóvenes aymaras de Tarapacá, tanto en sus pueblos de orígenes, con ocasión de las fiestas patronales o en la ciudad, siguen articulándose en torno a esta música. La proliferación de grupos musicales así lo indica.

IQUIQUE (CHILE), MARZO 2007

RECIBIDO: ABRIL 2007

ACEPTADO: JUNIO 2007

\section{REFERENCIAS BIBLIOGRÁFICAS}

CANDAU, Joel (2001): Memoria e identidad. Buenos Aires: Ediciones del Sol.

Cueto, JuAn (1982): Mitologías de la modernidad. Barcelona: Colección Salvat.

GONZÁLEZ, JULIÁN (1987): «Los hijos de la desintegración cultural. Jóvenes emigrados aymaras». Cuaderno de Investigación Social N²3. Iquique: Centro de Investigación de la Realidad del Norte.

GUERRERO, BERNARDO (1999): Hasta que el cuerpo aguante. La dinámica sociocultural del consumo de drogas. Iquique: Ediciones El Jote Errante.

GUERRERO, Víctor (1995) «El mapa social de la pobreza urbana en Iquique». Cuaderno de Investigación Social №36. Iquique: Centro de Investigación de la Realidad del Norte.

Hurtado, Wilfredo (1995): Chicha peruana. Música de los nuevos migrantes. Lima: Grupo de Investigaciones Económicas.

PASSERINI, LAURA (1996): «La juventud, metáfora del cambio social (dos debates sobre los jóvenes en la Italia fascista y en los Estados Unidos durante los años cincuenta)». En GIOVANNI LEVI y JEAN-ClaUde SCHMitT (editores): Historia de los jóvenes II. La edad contemporánea. Madrid: Taurus.

PODESTÁ, JUAN (2004): La invención de Tarapacá. Estado y desarrollo regional en Chile. Iquique: Ediciones Campvs.

Pratt, Henry (editor) (1963): Diccionario de sociología. México: Fondo de Cultura Económica.

KeSSEL, JUAN VAN (1980): Holocausto al progreso. Los aymaras de Tarapa- 
cá. Amsterdam: CEDLA.

RAMÍREZ PAREDES, JUAN (2006): «Música y sociedad: la preferencia musical como base de la identidad social». Sociológica $\mathrm{N}^{\circ} 60$. México: Universidad Autónoma Metropolitana.

WARREN, HowARD (editor) (1970): Diccionario de psicología. México: Fondo de Cultura Económica. 